\title{
Short Communication: \\ Evaluation of drought tolerance indices for genotype selection of foxtail millet (Setaria italica)
}

\author{
SHERLY LAPUIMAKUNI ${ }^{1, v}$, NURUL KHUMAIDA ${ }^{2, v v}$, SINTHO WAHYUNING ARDIE, ${ }^{3, v v v}$ \\ ${ }^{1}$ Program of Plant Breeding and Biotechnology, Institut Pertanian Bogor. Jl. Raya Dramaga, Bogor 16680, West Java, Indonesia. \\ Tel: +62-251-8629353, `email: lapuimakunisherly@gmail.com, \\ ${ }^{2}$ Department of Agronomy and Horticulture, Faculty of Agriculture, Institut Pertanian Bogor. J1. Raya Dramaga, Bogor 16680, West Java, Indonesia. \\ Tel: +62-251-8629353, "vemail: nurul_khumaida@apps.ipb.ac.id, vws sintho_wa@apps.ipb.ac.id
}

Manuscript received: 13 May 2018. Revision accepted: 16 September 2018.

\begin{abstract}
Lapuimakuni S, Khumaida N, Ardie SW. 2018. Evaluation of drought tolerance indices for genotype selection of foxtail millet (Setaria italica). Trop Drylands 2: 37-40. Foxtail millet (Setaria italica (L.) Beauv) is one of underutilized crops cultivated for its nutritious grain and its relative tolerance to drought stress. However, the drought tolerance level of this crop is varied between genotypes. Thus, breeding approaches to develop drought-tolerant foxtail millet variety are of great importance. This study aimed to: (i) evaluate several drought tolerance indices to determine one or more predictors among studied indices, and (ii) identify the drought tolerance level of the evaluated foxtail millet genotypes. Eight foxtail millet genotypes were planted in a greenhouse with a completely randomized design and five replications under both drought and normal watering conditions. Staggered planting was applied to synchronize flowering time. Watering was withheld for 15 days during the flowering period, and then plants were re-watered until harvest time. Multiple indices for drought tolerance were calculated based on the potential yield (Yp) under non-stress and yield (Ys) under stress conditions. Based on the correlation, principal component analysis, and cluster analysis, yield index (YI) and harmonic mean (HM) were considered the best indices for the selection of drought-tolerant foxtail millet genotypes. By using the best indices, two foxtail millet genotypes (ICERI-5 and ICERI-6) were considered drought tolerant genotypes.
\end{abstract}

Keywords: drought tolerance index, selection tools, staggered planting, underutilized crop

\section{INTRODUCTION}

Drought is one of the most significant abiotic stresses impeding global crop production. Foxtail millet [Setaria italica (L) Beauv.] is one of the staple crops potentially developed as functional foods, especially in drought-prone areas. Foxtail millet is reported to be relatively tolerant to drought (Lata et al. 2010; Karyudi and Fletcher 2003). The nutritious value of this cereal, such as low glycaemic index (Jali et al. 2012), high in protein content and rich in dietary fiber (Amadou et al. 2013), and containing anti-oxidant (Almaski et al. 2017), has made foxtail millet is potentially developed as a functional food. Zhang et al. (2012) also reported the potential of this crop as bio-energy source.

Although relatively tolerant to drought, the tolerance level of foxtail millet to drought stress varies among genotypes (Begum et al. 2013). Selecting highly droughttolerant foxtail millet genotypes is therefore of great importance. Proper selection method is crucial in determining the best genotype for particular traits. The adverse effect of drought stress depends significantly on the time and duration of the stress. Matsuura et al. (2012) reported that drought stress during early flowering period leads to the most significant productivity loss in foxtail millet. Therefore, drought stress needs to be applied during the early flowering period to select tolerant genotypes accurately. However, Sulistiyowati (2015) reported that the flowering time of foxtail millet varied between genotypes. Staggered planting method for flowering time synchronization has been applied for drought tolerant wheat screening (Briggs et al. 1999).

The selection index is one of the selection tools commonly used in plant breeding. Mardeh et al. (2006) reported that genotypes with high productivity under optimum conditions may not always be drought tolerant. In this study, we analyzed several selection indices to determine the best selection index for the drought-tolerant trait in foxtail millet and to select the tolerant foxtail millet genotypes.

\section{MATERIALS AND METHODS}

\section{Study area}

This research was carried out in the Cikabayan greenhouse, Department of Agronomy and Horticulture, Faculty of Agriculture, Bogor Agricultural University, Indonesia from November 2016 to April 2017.

\section{Procedures}

A completely randomized design was used in this experiment, consisting of two factors and five replications. The first factor was foxtail millet genotype and consisted of 8 genotypes (i.e. ICERI-2, ICERI-3, ICERI-4, ICERI-5, 
ICERI-6, ICERI-7, ICERI-9, and ICERI-10) obtained from Indonesian Cereals Research Institute. The second factor was the drought stress, comprised of normal watering and 15 days of no-watering during flowering period.

The seed of each genotype was planted in a 5 L-pot containing planting medium of soil: sand $(1: 1, \mathrm{v} / \mathrm{v})$. Seeds were sown according to the flowering time (Sulistiyowati 2015) in staggered planting method. Watering was withheld for 15 days during flowering period, and then plants were re-watered until harvest time. Grain weight per plant was weighed and used for the analysis.

\section{Data analysis}

Drought tolerance indices were calculated following various authors (Fischer and Maurer 1978; Bidinger et al. 1978; Bouslama and Schapaugh 1984; Gavuzzi et al. 1997; Farshadfar and Sutka 2002; Moosavi et al. 2008; Farshadfar and Javadinia 2011; Ali et al. 2013). The calculated drought indices were then further analyzed using principal component analysis, correlation analysis, and cluster analysis to determine the best selection indices for drought stress, and to select the most tolerant foxtail millet genotype(s) under drought stress.

\section{RESULTS AND DISCUSSION}

Drought stress in the period of 15 days during early flowering time decreased grain weight per plant of foxtail millet by $87 \%$ compared to the non-stressed condition (Table 1). ICERI-7, ICERI-5, and ICERI-6 genotypes showed the highest grain weight per plant under drought stress (Ys), while ICERI-3, ICERI-7 and ICERI-4 genotypes showed the highest grain weight per plant under optimum condition (Yp). The highest TOL value was demonstrated by ICERI-3, ICERI-4, and ICERI-2 genotypes, indicating that drought stress caused the highest loss of grain weight per plant on these genotypes. In contrast, ICERI-5 and ICERI-6 showed the lowest TOL, suggesting that these genotypes were only slightly affected by drought stress. Similar genotype rank was obtained based on Ys, YI (Yield index), and HM (Harmonic mean), indicating that the two selection indices could select foxtail millet genotype with high grain weight under drought stress.

Based on correlation analysis, grain weight per plant under non-stressed conditions (Yp) had a very weak association $\left(r=0.08^{\text {ns }}\right)$ with grain weight per plant under stressed conditions (Ys), indicating that high potential yield under optimum conditions does not necessarily result in high yield under drought stress condition. Therefore, genotype selection based on the yield under optimum conditions will not be efficient to select drought-tolerant foxtail millet genotype. Anwar et al. (2011) also reported a positive but non-significant association between the yield of wheat in stress and non-stress condition. Two selection indices, YI $\left(r=1.00^{* *}\right)$ and HM $\left(r=0.99^{* *}\right)$, showed a very high and significant association with grain weight per plant under stress (Ys).

The principal component analysis showed that the first components (PC1 and PC2) explained about $96.7 \%$ of the total variance (Table 2). The first PC explained $66.5 \%$ of the obtained variation and showed high coordination between Ys, GMP (Geometric mean productivity), STI (Stress tolerance index), YI, YSI YSI (Yield stability index), HM, DI (Drought resistance index), RDI (Relative drought index), and K2STI. The PC2 explained $30.2 \%$ of the total obtained variation and showed high coordination between Ys, YI and HM. Taken together, the data presented in Table 1 and Table 2 clearly indicates YI and $\mathrm{HM}$ as the best selection indices for foxtail millet under drought stress conditions.

Table 1. The mean grain weight per plant of eight foxtail millet genotypes under stressed (Ys) and non-stressed (Yp) conditions and their corresponding tolerance indices

\begin{tabular}{|c|c|c|c|c|c|c|c|c|c|c|c|c|c|c|c|c|}
\hline Genotype & Ys & Yp & SSI & TOL & GMP & MP & STI & YI & YSI & HM & SDI & DI & RDI & SSPI & K1STI & K2STI \\
\hline ICERI2 & 0.33 & .56 & 11 & 0.23 & 1.87 & 5.45 & .04 & .27 & 0.03 & 0.64 & .97 & 0.01 & 0.24 & 53.33 & 0.05 & 0.00 \\
\hline & & & 01 & & & & & & & & & & & & & \\
\hline & & & & 10. & & & & & & & & & & & & \\
\hline ICEF & & 7.0 & & & & & & & & & & & & & & \\
\hline & & & & & & & & & & & & & & & & \\
\hline & & & & & & & & & & & & & & & & \\
\hline & & & & & & & & & & & & & & & & \\
\hline ICERI10 & 0 & 6.85 & 1.14 & 6.77 & .74 & & .01 & 0.06 & 0.01 & 0.16 & & 0.0 & 0.09 & 35.31 & 00 & .00 \\
\hline Min & & 6.85 & 0.77 & 4.75 & 74 & & 1 & 0.06 & 01 & 0.16 & & 0.0 & 0.09 & 24.75 & 00 & .00 \\
\hline & 2.66 & 13.05 & 1.14 & 11.50 & & 7.30 & & 2.1 & 0.3 & 4.32 & 0. & 0. & 2.53 & 59.94 & 0.49 & 1.53 \\
\hline Mean & 1.25 & 9.59 & 0.99 & 8.35 & 3.14 & 5.42 & 0.13 & 1.00 & 0.14 & 2.06 & 0.86 & 0.21 & 1.05 & 43.52 & 0.16 & 0.35 \\
\hline StdDev & 0.98 & 2.31 & 0.14 & 2.44 & 1.58 & 1.29 & 0.11 & 0.79 & 0.12 & 1.52 & 0.12 & 0.24 & 0.91 & 12.72 & 0.18 & 0.53 \\
\hline
\end{tabular}

Note: Ys: grain weight per plant (g) under stressed condition; Yp: grain weight per plant (g) under non-stressed condition; SSI: Stress susceptibility index; TOL: Tolerance; GMP: Geometric mean productivity; MP: Mean productivity; STI: Stress tolerance index; YI: Yield index; YSI: Yield stability index; HM: Harmonic mean; SDI: Sensitivity drought tolerant; DI: Drought resistance index; RDI: Relative drought index; SSPI: Stress susceptibility percentage index; MSTI: Modified stress tolerance index: K1STI, K2STI. Values in bold are indicating the three highest values of Ys or Yp. 
Table 2. Principal component analysis for drought tolerance indices in foxtail millet

\begin{tabular}{|c|c|c|c|c|c|c|c|c|}
\hline Variables & PC1 & PC2 & PC3 & PC4 & PC5 & PC6 & PC7 & PC8 \\
\hline Ys & 0.306 & 0.029 & 0.006 & -0.060 & 0.094 & 0.017 & 0.325 & -0.403 \\
\hline Yp & 0.004 & 0.450 & 0.208 & 0.169 & -0.014 & 0.045 & 0.066 & 0.212 \\
\hline SSI & -0.289 & 0.134 & -0.239 & -0.073 & 0.067 & -0.218 & 0.173 & -0.301 \\
\hline TOL & -0.119 & 0.415 & 0.194 & 0.184 & -0.051 & 0.036 & -0.068 & -0.412 \\
\hline GMP & 0.280 & 0.174 & 0.135 & -0.258 & 0.441 & -0.571 & -0.522 & -0.036 \\
\hline MP & 0.119 & 0.415 & 0.189 & 0.129 & 0.023 & 0.047 & 0.182 & -0.099 \\
\hline STI & 0.275 & 0.190 & -0.207 & -0.226 & 0.011 & -0.063 & 0.156 & 0.195 \\
\hline YI & 0.306 & 0.029 & 0.006 & -0.060 & 0.094 & 0.017 & 0.325 & -0.116 \\
\hline YSI & 0.289 & -0.134 & 0.239 & 0.073 & -0.067 & 0.218 & -0.173 & -0.446 \\
\hline HM & 0.303 & 0.066 & 0.022 & -0.182 & 0.245 & 0.057 & 0.436 & 0.260 \\
\hline SDI & -0.289 & 0.134 & -0.239 & -0.073 & 0.067 & -0.218 & 0.173 & 0.081 \\
\hline DI & 0.294 & -0.109 & -0.025 & 0.417 & -0.541 & -0.631 & 0.143 & 0.045 \\
\hline RDI & 0.289 & -0.134 & 0.239 & 0.073 & -0.067 & 0.218 & -0.173 & 0.330 \\
\hline SSPI & -0.119 & 0.415 & 0.194 & 0.184 & -0.051 & 0.036 & -0.068 & 0.288 \\
\hline K1STI & 0.192 & 0.332 & -0.337 & -0.488 & -0.575 & 0.176 & -0.253 & -0.051 \\
\hline K2STI & 0.260 & 0.124 & -0.665 & 0.544 & 0.284 & 0.202 & -0.226 & -0.001 \\
\hline StdDev & 3.263 & 2.198 & 0.632 & 0.324 & 0.143 & 0.032 & 0.009 & 0.000 \\
\hline Variance proportion & 0.665 & 0.302 & 0.025 & 0.007 & 0.001 & 0.000 & 0.000 & 0.000 \\
\hline Cumulative proportion & 0.665 & 0.967 & 0.992 & 0.999 & 1.000 & 1.000 & 1.000 & 1.000 \\
\hline
\end{tabular}

Note: PC: principal component; Ys: grain weight per plant (g) under stressed condition; Yp: grain weight per plant (g) under nonstressed condition; SSI: Stress susceptibility index; TOL: Tolerance; GMP: Geometric mean productivity; MP: Mean productivity; STI: Stress tolerance index; YI: Yield index; YSI: Yield stability index; HM: Harmonic mean; SDI: Sensitivity drought tolerant; DI: Drought resistance index; RDI: Relative drought index; SSPI: Stress susceptibility percentage index; MSTI: Modified stress tolerance index: K1STI, K2STI. Values in bold indicate indices highly coordinated with Ys in each PC

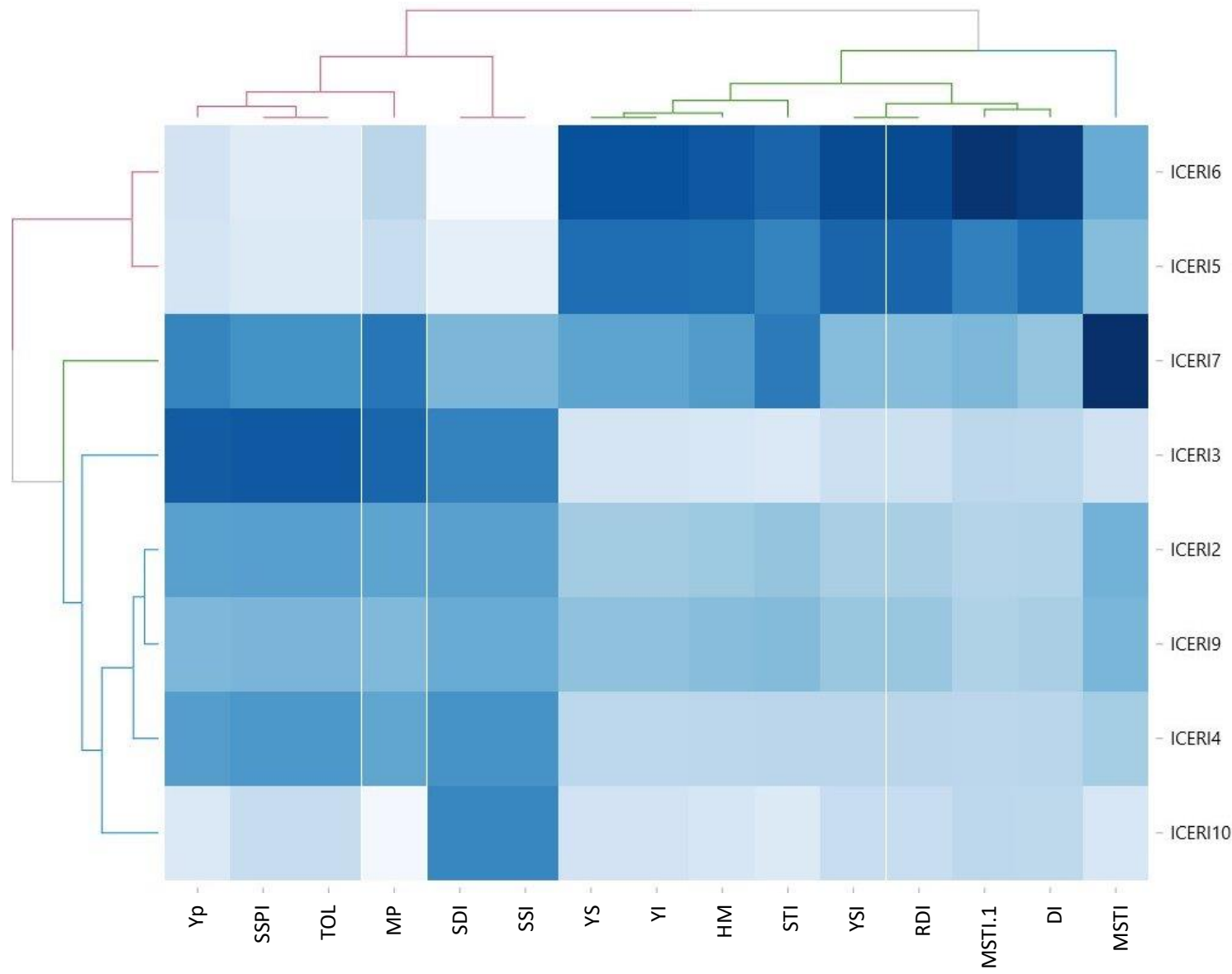

Figure 1. Clustergram showing the relation of selection indices for drought stress with 8 foxtail millet genotypes 
Multivariate statistical analysis, such as cluster analysis, is an important approach for genotype classification based on their relatedness. Figure 1 shows the clustergram that clusters the tolerant and sensitive foxtail millet genotypes in different groups. In Figure 1, dark blue color in the column indicates high association between particular genotype and selection index. The interaction column between ICERI-6 or ICERI-5 genotype with grain weight per plant under non-stressed condition (Yp) shows very light blue color, indicating that these two genotypes have low yield under non-stressed conditions. In contrast, the interaction column between ICERI-6 or ICERI-5 genotype with grain weight per plant under stressed condition (Ys) shows very dark blue color, indicating that these two genotypes have high yield under the stressed condition. The clustergram classified ICERI-5 and ICERI-6 in the tolerant group, while ICERI-3 and ICERI-10 genotypes were classified as the sensitive group.

In this study, drought stress for 15 days during the early flowering period caused $87 \%$ decrease in yield, which can be considered severe drought stress. Ali and El-Sadek (2016) reported that moderate drought stress is more suitable to select drought-tolerant genotype in wheat. Therefore, further evaluation under various drought stress duration is necessary to validate the selected indices (YI and $\mathrm{HM}$ ) obtained in this study.

\section{ACKNOWLEDGEMENTS}

The research was supported by Ministry of Research, Technology, and Higher Education of the Republic of Indonesia through PUPT scheme Batch 2017.

\section{REFERENCES}

Ali MB and El-Sadek AN. 2016. Evaluation of drought tolerance indices for wheat (Triticum aestivum L.) under irrigated and rainfed conditions. Commun Biometry Crop Sci 11: 77-89.

Almaski A, Thondre S, Lightowler H, Coe S. 2017. Determination of the polyphenol and antioxidant activity of different types and forms of millet. Proc Nutr Soc 76: OCE1, E5. DOI: $10.1017 /$ S0029665117000052.

Amadou I, Gounga, ME, Le GW. 2013. Millets: Nutritional composition, some health benefits, and processing $-\mathrm{A}$ review. Emirates J Food Agric 25: 501-508.

Anwar J, Subhani GM, Hussain M, Ahmad J, Hussain M, Munir M. 2011 Drought tolerance indices and their correlation with yield in exotic wheat genotypes. Pak J Bot 43: 527-1530.
Begum F, Sultana R, Nessa A. 2013. Screening of drought-tolerant foxtail millet (Setaria italica Beauv) germplasm. Bangladesh J Sci Ind Res 48: $265-270$

Bidinger FR, Mahalakshmi V, Rao GDP. 1978. Assessment of drought resistance in pearl millet (Pennisetum americanum (L.) Leeke). I. Factors affecting yields under stress. Aust J Agric Res 38: 37-48.

Bouslama M, Schapaugh WT. 1984. Stress tolerance in soybeans. I. Evaluation of three screening techniques for heat and drought tolerance. Crop Sci 24: 933-937.

Briggs KG, Kiplagat OK, Johnson-Flanagan AM. 1999. Effects of preanthesis moisture stress on floret sterility in some semi-dwarf and conventional height spring wheat cultivars. Can J Plant Sci 79: 515520 .

Farshadfar E, Javadinia J. 2011. Evaluation of chickpea (Cicer arietinum L.) genotypes for drought tolerance. Seed Plant Improv J 27: 517-537.

Farshadfar E, Sutka J. 2002. Screening drought tolerance criteria in maize. Acta Agronomica Hungaria 50: 411-416.

Fischer RA, Maurer R. 1978. Drought resistance in spring wheat cultivars. I. Grain yield responses. Crop Pasture Sci 29: 897-912.

Gavuzzi P, Rizza F, Palumbo M, Campaline RG, Ricciardi GL, Borgh B. 1997. Evaluation of field and laboratory predictors of drought and heat tolerance in winter cereals. Canadian J Plant Sci 77: 523-531.

Jali MV, Kamatar MY, Jali SM, Hiremath MB, Naik RK. 2012. Efficacy of value-added foxtail millet therapeutic food in the management of diabetes and dyslipidemia in type 2 diabetic patients. Recent Res Sci Technol 4: 3-4.

Karyudi and Fletcher, RJ. 2003). Osmoregulation in birdseed millet under conditions of water stress II. Variation in F3 lines of Setaria italica and its relationship to plant morphology and yield. Euphytica 132: 191-197.

Lan J. 1998. Comparison of evaluating methods for agronomic drought resistance in crops. Acta Agric Bot Sin 7: 85-87.

Lata C, Sahu PP, Prasad M. 2010. Comparative transcriptome analysis of differentially expressed genes in foxtail millet (Setaria italica L.) during dehydration stress. Biochem Biophys Res Commun 393: 720727.

Mardeh ASS, Ahmadi A, Poustini K, Mohammadi V. 2006. Evaluation of drought resistance indices under various environmental conditions. Field Crops Res 98 (2): 22-229.

Matsuura A, Tsuji W, An P, Inanaga S, Murata K. 2012. Effect of pre- and post-heading water deficit on growth and grain yield of four millets. Plant Prod Sci 15: 323-331.

Moosavi SS, Yazdi SB, Naghavi MR, Zali AA, Dashti H, Pourshahbazi A. 2008. Introduction of new indices to identify relative drought tolerance and resistance in wheat genotypes. Desert 12:165-178.

Rosielle AA, Hamblin J. 1981. Theoretical aspects of selection for yield in stress and non-stress environment. Crop Sci 21: 943-946.

Schneider KA, Rosales SR, Ibarra PF, Cazares EB, Acosta-Gallegos JA, Ramirez VP, Wassimi N, Kelly JD. 1997. Improving common bean performance under drought stress. Crop Sci 37: 43-50.

Sulistiyowati E. 2015. Characterization of ten foxtail millet (Setaria italica (L) Beauv) accessions in a greenhouse. [Hon. Thesis]. Bogor Agricultural University, Bogor.[Indonesian]

Zhang G, Liu X, Quan Z, Cheng S, Xu X, Pan S, Xie M, Zeng P, Yue Z, Wang W. 2012. Genome sequence of foxtail millet (Setaria italica) provides insights into grass evolution and biofuel potential. Nature Biotec 30: 549-556. 